\title{
Glycemic Control in a Real-Life Setting in Patients with Type 2 Diabetes Treated with IDegLira at a Single Swiss Center
}

Daniela Sofra

Received: December 8, 2016 / Published online: February 20, 2017

(C) The Author(s) 2017. This article is published with open access at Springerlink.com

\section{ABSTRACT}

Introduction: The aim of the present study was to describe clinical outcomes in a real-world population of Swiss patients with long-standing, poorly controlled type 2 diabetes after switching to IDegLira [a combination of insulin degludec (IDeg) and liraglutide (Lira)].

Methods: This was a prospective, open-label, single-center observational follow-up at the Cabinet Medical de Diabétologie, Lausanne, Switzerland, of 61 patients $\left[\mathrm{HbA}_{1 \mathrm{c}} \quad 9.2 \%\right.$ $(77 \mathrm{mmol} / \mathrm{mol})$ and $56.1 \mathrm{U}$ total insulin] initiated with IDegLira at 20 dose steps (20 U IDeg/ $0.72 \mathrm{mg}$ Lira), except in insulin-naïve patients who began treatment at 16 dose steps. Thereafter, the dose was titrated by four dose steps once weekly, according to individualized fasting blood glucose targets. Information about glycemic control, total insulin dose, weight, and blood pressure, along with any adverse events,

Enhanced content To view enhanced content for this article go to http://www.medengine.com/Redeem/ A987F060603278BE.

Electronic supplementary material The online version of this article (doi:10.1007/s13300-017-0234-y) contains supplementary material, which is available to authorized users.

D. Sofra $(\bowtie)$

FMH Diabétologie et Endocrinologie, Cabinet

Médical, Lausanne, Switzerland

e-mail: daniela.sofra@svmed.ch was collected from medical records and patient reports during clinic visits at baseline, 3 months, and end of follow-up.

Results: Over 6 months of follow-up, mean $\mathrm{HbA}_{1 \mathrm{c}}$ improved (decrease of $1.7 \%$ ) to $7.5 \%$ with concomitant weight loss. Switching to IDegLira resulted in a lower $(-14.6 \mathrm{U})$ total insulin dose compared with baseline for those patients previously on insulin. There were no episodes of severe hypoglycemia during treatment with IDegLira. There were small decreases in both mean systolic and mean diastolic blood pressure with IDegLira. Six patients discontinued treatment early because of adverse gastrointestinal events with IDegLira.

Conclusion: Switching to IDegLira, mostly from regimens using insulin in conjunction with oral antidiabetic medications in a realworld population of patients with type 2 diabetes, resulted in improved glucose control with a lower insulin dose and weight loss.

Keywords: IDegLira; Incretin; Insulin; Observational study; Type 2 diabetes

\section{INTRODUCTION}

Typically, patients with newly diagnosed type 2 diabetes (T2D) are initially encouraged to attempt to lower their blood glucose with nutrition and lifestyle management. As a result of the progressive pathophysiology of T2D, 
however, further treatment intensification will eventually be required. The next step usually involves addition of oral antidiabetic medications, often followed by exogenous insulin therapy. However, patients may resist treatment intensification, particularly when insulin is involved, because of concerns about hypoglycemia, body weight gain, and/or the complexity of such regimens. Incretin-based therapies such as dipeptidyl peptidase- 4 inhibitors or glucagon-like peptide 1 (GLP-1) receptor agonists represent another option: these drugs carry a low risk of hypoglycemia and typically do not cause weight gain $[1,2]$.

IDegLira (Xultophy ${ }^{\circledR}$, Novo Nordisk A/S, Bagsvaerd, Denmark) is a fixed-ratio combination of insulin degludec (IDeg; $100 \mathrm{U} / \mathrm{mL}$ ) and liraglutide (Lira; $3.6 \mathrm{mg} / \mathrm{mL}$ ). Insulin degludec is a basal insulin with an ultra-long duration of action and a flat pharmacodynamic profile $[3,4]$, and is associated with a lower risk of hypoglycemia than insulin glargine U100 $[5,6]$. Liraglutide is a human GLP-1 analogue given once daily; it stimulates insulin secretion and lowers glucagon secretion in a glucose-dependent fashion, thus posing a low risk of hypoglycemia while helping to control both fasting and post-meal glucose levels [7].

Liraglutide delays gastric emptying and reduces feelings of hunger. It is also used as a treatment for obesity, and therefore is often associated with weight loss in patients with diabetes $[8,9]$. The pharmacokinetic properties of the two individual components, insulin degludec and liraglutide, are preserved in the fixed-ratio combination product IDegLira [10]. IDegLira is administered in dose steps (1 U insulin degludec and $0.036 \mathrm{mg}$ liraglutide) up to a maximum of 50 dose steps, corresponding to $50 \mathrm{U}$ of insulin degludec and $1.8 \mathrm{mg}$ of liraglutide.

The complementary mode of action of its two components means that IDegLira has the potential to be advantageous for patients with T2D who need to intensify therapy to achieve better glycemic control, but who may be reluctant to do so because of concerns about hypoglycemia, weight gain, and/or treatment complexity. In large, randomized, controlled, treat-to-target trials both in insulin-naïve
$[11,12]$ and insulin-experienced patients $[13,14]$, IDegLira has been shown to improve glycemic control without increasing body weight or risk of hypoglycemia.

The beneficial effects shown in clinical trials, however, are achieved in cohorts with strictly defined inclusion and exclusion criteria, so it is also important to gauge how well IDegLira will perform in the more heterogeneous populations of patients encountered in real-world practice. Several reports indicate that, when used individually in real-world populations, insulin degludec [15-18] and liraglutide [19, 20] each retain the benefits demonstrated in prior randomized controlled trials. This study adds to the body of real-world data by describing outcomes in Swiss patients with a long duration of T2D who were empirically selected for treatment with IDegLira.

\section{METHODS}

This was a prospective, open-label, single-center observational follow-up at the Cabinet Medical de Diabétologie in Lausanne, Switzerland, of all consecutive patients starting IDegLira between December 2014 and July 2015.

Patients began treatment with IDegLira for the following indications: not being well controlled under current treatment $\left(\mathrm{HbA}_{1 \mathrm{c}}\right.$ greater than $8.0 \%$ ), current treatment being too complicated for the patient (more than two oral antidiabetic medications and more than one injection daily), or it was believed the patient would benefit from the addition of the liraglutide component of IDegLira for weight management. No patients were excluded; however, it should be noted that in Switzerland, treatment with GLP-1 receptor agonists is reimbursed only for those patients whose body mass index (BMI) exceeds $28 \mathrm{~kg} / \mathrm{m}^{2}$. All procedures followed were in accordance with the ethical standards of the responsible committee on human experimentation (institutional and national) and with the Helsinki Declaration of 1964, as revised in 2013 [21]. Informed consent was obtained from all patients for being included in the study. The study was approved by the ethics 
committee for research in human beings in Lausanne, Switzerland.

IDegLira was initiated at 20 dose steps (20 U IDeg/0.72 mg liraglutide), except in insulin-naïve patients who began treatment at 16 dose steps. Thereafter, the dose was titrated in four dose steps once weekly, according to individualized fasting blood glucose targets. The individual $\mathrm{HbA}_{1 \mathrm{c}}$ target was set according to the European Association for the Study of Diabetes (EASD) recommendations. This value was converted to fasting plasma glucose for the patient. Patients were instructed to increase the dose of IDegLira by increments of four dose steps per week until achievement of the negotiated and individualized target.

For those patients requiring high doses of insulin (more than 50 units), a transition phase was included with addition of a slow-acting insulin during titration of IDegLira. If a patient reached the maximum of 50 dose steps and had still not reached good control, a second basal insulin was added (this was only necessary for one patient). Other concomitant therapies were allowed on the basis of physician and patient preference. At the time of switching treatment, each patient received a reminder on recommendations for following a balanced diet appropriate for type 2 diabetes, as well as encouragement to engage in at least $30 \mathrm{~min}$ of physical activity daily.

Information about glycemic control, total insulin dose, weight and blood pressure, as well as any adverse events, was collected from medical records and patient reports during clinic visits at baseline, at 3 months, and at the end of follow-up. Severe hypoglycemia was defined as events requiring the assistance of a third party.

\section{RESULTS}

A total of 61 patients with T2D were followed up, with six (one male, five female) discontinuing treatment early because of adverse gastrointestinal events such as nausea and vomiting. Baseline demographics and prior diabetes treatment for all patients are shown in Table 1 . Almost all patients ( $n=56,91.8 \%)$ had been using insulin, and the population could be characterized as very overweight (mean BMI $34.3 \mathrm{~kg} / \mathrm{m}^{2}$ ) and in poor glycemic control (mean $\mathrm{HbA}_{1 \mathrm{c}}$ 9.17\%). Most patients continued with other concomitant therapy (sulfonylurea only: $n=1,1.6 \%$; metformin only: $n=36$, $59.0 \%$; metformin + sodium-glucose transporter-2 inhibitors: $n=9,14.8 \%$; metformin + sulfonylurea: $n=2, \quad 3.3 \% ; \quad$ and metformin + basal insulin: $n=1,1.6 \%$ ). Twelve $(19.7 \%)$ patients did not use any other therapy besides IDegLira for their diabetes.

There were several clinically important benefits from switching to IDegLira for the 55 patients who completed 6 months of follow-up: mean $\mathrm{HbA}_{1 \mathrm{c}}$ improved (decrease of $1.7 \%$ ) to $7.5 \%$ (Fig. 1a) and there was concomitant weight loss (Fig. 1b). Furthermore, switching to IDegLira resulted in a lower $(-14.6 \mathrm{U})$ total insulin dose compared with baseline for those patients previously on insulin (Fig. 1c). Only one patient required a second basal insulin. A total of $20 / 61(32.8 \%)$ of all patients and $20 / 55$ (36.4\%) of those who continued treatment required the maximum dose (50 dose steps) of IDegLira. There were small decreases in both mean systolic and mean diastolic blood pressure after treatment with IDegLira (Fig. 1d). When data from the six patients who did not complete follow-up were included in the calculation of baseline values, the decreases in $\mathrm{HbA}_{1 \mathrm{c}}$, insulin dose, and blood pressure did not change substantially. However, the magnitude of mean weight reduction achieved was lower $(-0.4 \mathrm{~kg})$. For the four non-completers for whom baseline weight was available, the mean value $(77.5 \mathrm{~kg})$ was much lower than for the group of completers $(97.9 \mathrm{~kg})$.

There were no episodes of severe hypoglycemia during treatment with IDegLira in these Swiss patients.

\section{DISCUSSION}

Before starting treatment with IDegLira, this real-world population of mostly insulin-experienced $(91.9 \%)$ Swiss patients had a longer duration of diabetes (12.5 years), poorer glucose control $\left(\mathrm{HbA}_{1 \mathrm{c}} 9.2 \%\right)$, and greater mean body weight $(96.5 \mathrm{~kg})$ compared with patients 
Table 1 Baseline characteristics of 61 Swiss patients with type 2 diabetes who switched to IDegLira

\begin{tabular}{|c|c|c|c|}
\hline \multirow[t]{2}{*}{ Characteristic } & \multicolumn{3}{|l|}{ Value $^{a}$} \\
\hline & $\begin{array}{l}\text { All patients } \\
n=61\end{array}$ & $\begin{array}{l}\text { Males } \\
n=35\end{array}$ & $\begin{array}{l}\text { Females } \\
n=26\end{array}$ \\
\hline Age (years) & 57.3 (range $25-80$ ) & & \\
\hline Duration of diabetes (years) & 12.5 (range $1-31$ ) & 11.5 & 14.2 \\
\hline Weight (kg) & 96.5 & 103.2 & 87.5 \\
\hline BMI $\left(\mathrm{kg} / \mathrm{m}^{2}\right)$ & 34.3 & 33.9 & 34.9 \\
\hline $\mathrm{HbA}_{1 \mathrm{c}}(\%)$ & 9.2 & 9.0 & 9.4 \\
\hline $\mathrm{HbA}_{1 \mathrm{c}}(\mathrm{mmol} / \mathrm{mol})$ & 77 & 75 & 79 \\
\hline Systolic blood pressure $(\mathrm{mmHg})$ & 146.4 & 148.5 & 142.5 \\
\hline Diastolic blood pressure $(\mathrm{mmHg})$ & 88.4 & 90.8 & 84.3 \\
\hline \multicolumn{4}{|l|}{ Previous oral treatment $(n, \%)^{\mathrm{b}}$} \\
\hline Metformin & $23(37.7)$ & & \\
\hline Metformin + sitagliptin & $18(29.5)$ & & \\
\hline Gliclazide & $12(19.7)$ & & \\
\hline Liraglutide & $8(13.1)$ & & \\
\hline Metformin + saxagliptin & $5(8.2)$ & & \\
\hline Linagliptin & $3(4.9)$ & & \\
\hline Other ${ }^{c}$ & $10(16.4)$ & & \\
\hline \multicolumn{4}{|l|}{ Previous insulin treatment $(n, \%)$} \\
\hline Insulin degludec & $30(49.2)$ & & \\
\hline $\mathrm{NPH}$ & $9(14.8)$ & & \\
\hline Insulin glargine & $5(8.2)$ & & \\
\hline Insulin aspart/protamine crystallized insulin aspart & $4(6.6)$ & & \\
\hline Insulin aspart/insulin degludec mix & $3(4.9)$ & & \\
\hline Insulin detemir & $3(4.9)$ & & \\
\hline Insulin lispro/insulin lispro protamine/NPH & $2(3.3)$ & & \\
\hline None & $5(8.2)$ & & \\
\hline
\end{tabular}

$B M I$ body mass index, $H b A_{1 c}$ glycated hemoglobin, IDegLira insulin degludec/liraglutide, NPH neutral protamine Hagedorn

${ }^{\text {a }}$ Values are means unless otherwise specified

b Numbers add to $>100 \%$ owing to some patients being on multiple treatments

${ }^{c} \leq 2$ patients on any given medication

enrolled in randomized trials of a comparable duration of follow-up (26-52 weeks) $[11,13,14]$.
As was reported in the randomized clinical trials of IDegLira, in this follow-up of Swiss patients with T2D of relatively long duration, 

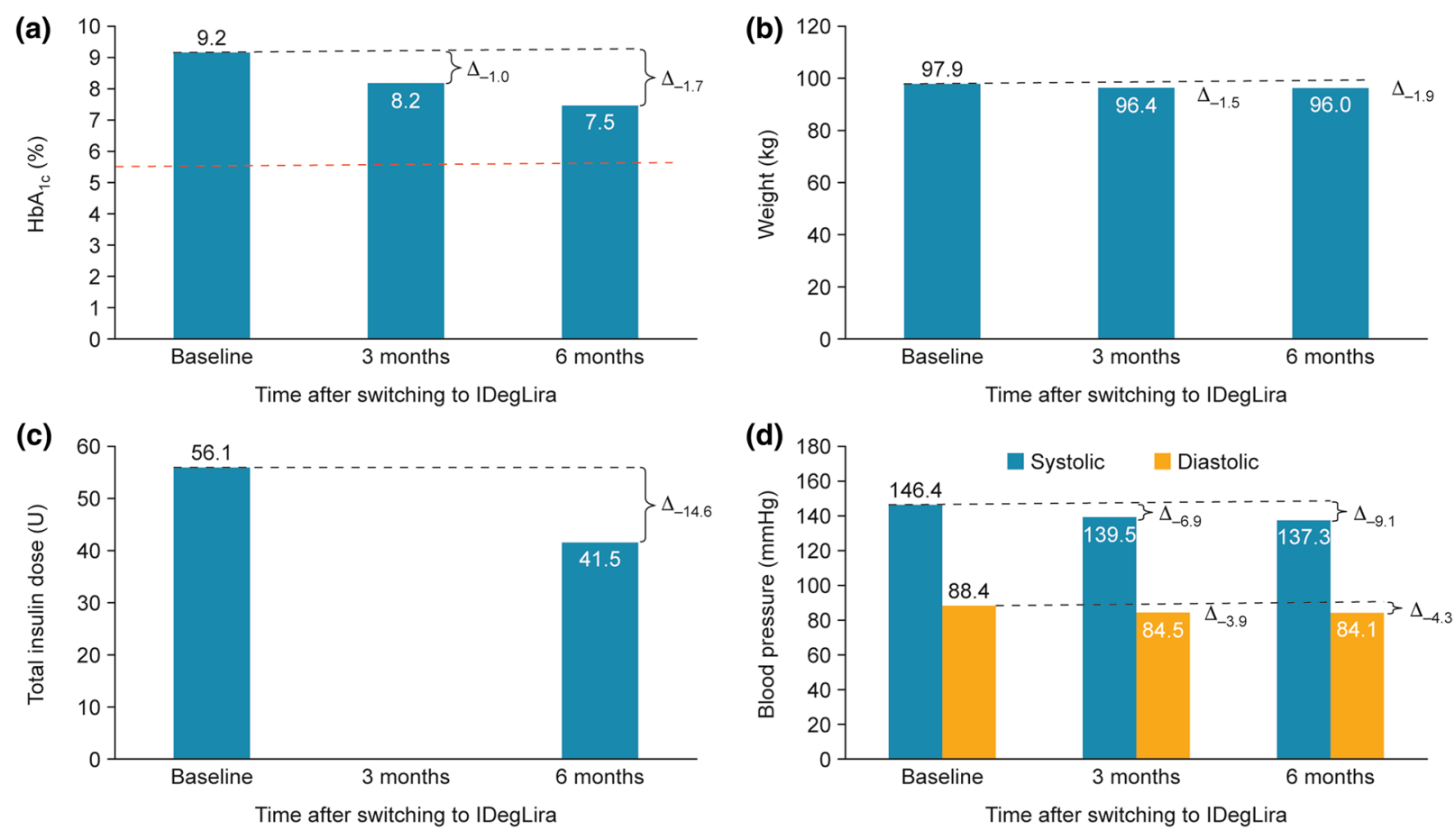

Fig. 1 Glucose control (a), body weight (b), insulin dose (c), and blood pressure (d) before and after switching to IDegLira in 55 Swiss patients who completed follow-up. Red dotted line in a shows normal value for $\mathrm{HbA}_{1 \mathrm{c}}(5.5 \%)$.

$H b A_{1 c}$ glycated hemoglobin, IDegLira insulin degludec/ liraglutide, $\Delta$ mean change from baseline

mean $\mathrm{HbA}_{1 \mathrm{c}}$ decreased after approximately 26 weeks of treatment. The reduction in $\mathrm{HbA}_{1 \mathrm{c}}$ in these poorly controlled patients $(-1.7 \%)$ was of a slightly lesser extent than those reported from the more restricted patient populations enrolled in randomized, treat-to-target trials $(-1.8 \%$ to $-1.9 \%)$ $[11,13,14]$. Furthermore, the improvement in $\mathrm{HbA}_{1 \mathrm{c}}$ in the Swiss patients was detectable at approximately 12 weeks (Fig. 1a), which is consistent with data from randomized clinical trials [22]. Unfortunately, as there were no observations in the period between switching to IDegLira and 12 weeks, it is not possible to determine precisely when the decrease began. These results are also consistent with a post hoc analysis of two randomized controlled trials, which showed that the reduction in $\mathrm{HbA}_{1 \mathrm{c}}$ was largely independent of disease duration or previous insulin dose [23]. By comparison, the reduction in weight among those patients completing follow-up $(-1.9 \mathrm{~kg})$ in this study was greater than that reported in

two randomized trials, $-0.5 \mathrm{~kg}$ [11] and $-1.4 \mathrm{~kg}$ [14], but less than that reported for another trial $(-2.7 \mathrm{~kg}[13])$.

It should be mentioned that, very often, a seasonal weight variation is observed, with an increase during winter and a decrease during summer. Despite the fact that the 6-month observation period for these patients went from the beginning of winter to spring, there was a trend towards weight loss.

The decrease in systolic blood pressure in these patients $(9.1 \mathrm{mmHg})$ is also consistent with results from randomized trials of liraglutide alone [7] and IDegLira [14].

The absence of any episodes of severe hypoglycemia is consistent with previously reported randomized trials of IDegLira in patients previously treated with insulin $[13,14]$. In these larger-scale studies, only one episode of severe hypoglycemia was reported and this occurred during exercise (mountain climbing) and was resolved after consumption of a sweet beverage [13]. 
Among the limitations of this study is the small sample size. This was fixed on the basis of the constraint of the observation period. For the chosen observation period, the number of patients included is representative of the volume of consultations performed by a private practice in a Swiss city. A longer period of observation would probably have better consolidated the data but it would have required a longer period and a greater workforce so as not to interfere with the usual functioning of the private practice. Data on adverse events such as hypoglycemia were not systematically solicited, nor were reported events assessed. Instead, they were recorded only if patients mentioned them during a follow-up visit. However, patients were generally very open about their experience with IDegLira during follow-up visits.

Patients initiated therapy at a higher dose of IDegLira (20 dose steps for insulin experienced, 16 dose steps for insulin naïve) than is recommended in the IDegLira prescribing information (16 dose steps for insulin experienced and 10 dose steps when transferring from oral therapy) [24]. This shows how clinical practice in a real-world setting differs from clinical trials. In a clinical trial, where patients are monitored closely and regularly, titration can be slower, and frequent contact with participants can be helpful in ensuring treatment compliance. In reallife practice, where visits and follow-up are much less frequent, it may be necessary to be more aggressive in the titration process so that patients sense improvement and therefore retain the motivation to continue with treatment. The trade-off for starting with a higher dose of IDegLira, of course, may be in the inability of some patients to continue therapy because of gastrointestinal side effects. Given the lower body weight among patients who discontinued in this follow-up study, a more individualized titration schedule might be warranted, taking into account factors such as body weight. Despite the starting dose of IDegLira in this study being higher than that recommended, patients' total insulin requirements were nevertheless reduced from those at baseline over 6 months, with the achievement of an improved and acceptable mean $\mathrm{HbA}_{1 \mathrm{c}}$. Had a treat-to-target approach been used, it is likely that $\mathrm{HbA}_{1 \mathrm{c}}$ could have been further reduced.

Some aspects of diabetes treatment, which are just as important as glycemic control, have not been formally evaluated in this observational analysis, but deserve to be mentioned here. According to patients' feedback, the process of changing treatment to IDegLira was itself helpful by increasing their motivation to better manage their diabetes. Examples include being more careful about what they eat and when, and engaging in more frequent self-measured blood glucose testing. This in turn has an impact on improving glycemia. For some patients, concurrent stressful life events (e.g., serious illness in a spouse, divorce) may have interfered with optimal diabetes management. In others, while switching treatment did not immediately result in improvements in glycemic control, there were nevertheless important benefits with respect to quality of life (e.g., being able to engage in more regular exercise owing to feeling less sick).

\section{CONCLUSION}

Switching to IDegLira, mostly from regimens of other insulin treatments in conjunction with oral antidiabetic medications in a real-world population in patients treated for T2D, resulted in improved glucose control with a lower insulin dose and without weight gain.

\section{ACKNOWLEDGEMENTS}

Article processing charges for this paper were funded by Novo Nordisk. Medical writing and submission support were provided by Gary Patronek and Daria Renshaw of Watermeadow Medical, an Ashfield company, part of UDG Healthcare plc, funded by Novo Nordisk A/S, Søborg, Denmark. The sponsor facilitated the translation between French and English but had no role in the collection or analysis of data or review of the article. The author had full access to all of the data in this study and takes complete responsibility for the integrity of the data and accuracy of the data analysis. The named author 
meets the International Committee of Medical Journal Editors (ICMJE) criteria for authorship for this manuscript, takes responsibility for the integrity of the work as a whole, and has given final approval for the version to be published.

Disclosures. Daniela Sofra declares no conflict of interest in the writing of this manuscript. She has collaborated regularly with several pharmaceutical companies, including Novo Nordisk.

Compliance with Ethics Guidelines. All procedures followed were in accordance with the ethical standards of the responsible committee on human experimentation (institutional and national) and with the Helsinki Declaration of 1964, as revised in 2013. Informed consent was obtained from all patients for being included in the study. The study was approved by the ethics committee for research in human beings in Lausanne, Switzerland.

Data Availability. All data generated or analyzed during this study are included as a supplementary information file.

Open Access. This article is distributed under the terms of the Creative Commons Attribution-NonCommercial 4.0 International License (http://creativecommons.org/licenses/ by-nc/4.0/), which permits any noncommercial use, distribution, and reproduction in any medium, provided you give appropriate credit to the original author(s) and the source, provide a link to the Creative Commons license, and indicate if changes were made.

\section{REFERENCES}

1. Madsbad S, Kielgast U, Asmar M, Deacon CF, Torekov SS, Holst JJ. An overview of once-weekly glucagon-like peptide-1 receptor agonists-available efficacy and safety data and perspectives for the future. Diabetes Obes Metab. 2011;13:394-407.

2. Karagiannis T, Liakos A, Bekiari E, et al. Efficacy and safety of once-weekly glucagon-like peptide 1 receptor agonists for the management of type 2 diabetes: a systematic review and meta-analysis of randomized controlled trials. Diabetes Obes Metab. 2015;17:1065-74.

3. Heise T, Nosek L, Bøttcher SG, Hastrup H, Haahr H. Ultra-long-acting insulin degludec has a flat and stable glucose-lowering effect in type 2 diabetes. Diabetes Obes Metab. 2012;14:944-50.

4. Haahr H, Heise T. A review of the pharmacological properties of insulin degludec and their clinical relevance. Clin Pharmacokinet. 2014;53:787-800.

5. Einhorn D, Handelsman Y, Bode BW, Endahl LA, Mersebach $\mathrm{H}$, King AB. Patients achieving good glycemic control $\left(\mathrm{HbA}_{1 \mathrm{c}}<7.0 \%\right)$ experience a lower rate of hypoglycemia with insulin degludec than with insulin glargine: a meta-analysis of phase 3A trials. Endocr Pract. 2015;21:917-26.

6. Ratner RE, Gough SC, Mathieu C, et al. Hypoglycaemia risk with insulin degludec compared with insulin glargine in type 2 and type 1 diabetes: a pre-planned meta-analysis of phase 3 trials. Diabetes Obes Metab. 2013;15:175-84.

7. Bode B. An overview of the pharmacokinetics, efficacy and safety of liraglutide. Diabetes Res Clin Pract. 2012;97:27-42.

8. Crane J, McGowan B. The GLP-1 agonist, liraglutide, as a pharmacotherapy for obesity. Ther Adv Chronic Dis. 2016;7:92-107.

9. Blonde L, Russell-Jones D. The safety and efficacy of liraglutide with or without oral antidiabetic drug therapy in type 2 diabetes: an overview of the LEAD 1-5 studies. Diabetes Obes Metab. 2009;11(Suppl. 3):26-34.

10. Kapitza C, Bode B, Ingwersen SH, Jacobsen LV, Poulsen P. Preserved pharmacokinetic exposure and distinct glycemic effects of insulin degludec and liraglutide in IDegLira, a fixed-ratio combination therapy. J Clin Pharmacol. 2015;55:1369-77.

11. Gough SC, Bode B, Woo V, et al. Efficacy and safety of a fixed-ratio combination of insulin degludec and liraglutide (IDegLira) compared with its components given alone: results of a phase 3 , open-label, randomised, 26-week, treat-to-target trial in insulin-naive patients with type 2 diabetes. Lancet Diabetes Endocrinol. 2014;2:885-93.

12. Gough SC, Bode BW, Woo VC, et al. One-year efficacy and safety of a fixed combination of insulin degludec and liraglutide in patients with type 2 diabetes: results of a 26 -week extension to a 26 -week main trial. Diabetes Obes Metab. 2015;17:965-73.

13. Buse JB, Vilsbøll T, Thurman J, et al. Contribution of liraglutide in the fixed-ratio combination of 
insulin degludec and liraglutide (IDegLira). Diabetes Care. 2014;37:2926-33.

14. Lingvay I, Pérez Manghi F, García-Hernández P, Norwood P, Lehmann L, Tarp-Johansen MJ, DUAL $\mathrm{V}$ Investigators, et al. Effect of insulin glargine up-titration vs insulin degludec/liraglutide on glycated hemoglobin levels in patients with uncontrolled type 2 diabetes: The DUAL V Randomized Clinical Trial. JAMA. 2016;315:898-907.

15. Kobuke K, Yoneda M, Nakanishi S, Ohno H, Maeda S, Egusa G. Efficacy and safety of insulin degludec in Japanese patients with type 1 and type 2 diabetes: 24-week results from the observational study in routine clinical practice. J Diabetes Investig. 2016;7:94-9.

16. Merchante-Alfaro AÁ, Pérez-Naranjo S, AbellánGaliana P, Rubio-Puchol O. Insulin degludec: the new standard long acting insulin analogue for people with type 1 diabetes? (Letter to the Editor). Endocr J. 2016;63:411-2.

17. Evans M, McEwan P, Foos V. Insulin degludec early clinical experience: does the promise from the clinical trials translate into clinical practice-a case-based evaluation. J Med Econ. 2015;18:96-105 (erratum in: J Med Econ. 2015;18:482).

18. Landstedt-Hallin L. Changes in $\mathrm{HbA}_{1 \mathrm{c}}$, insulin dose and incidence of hypoglycemia in patients with type 1 diabetes after switching to insulin degludec in an outpatient setting: an observational study. Curr Med Res Opin. 2015;31:1487-93.
19. Heymann A, Maor Y, Goldshtein I, Todorova L, Schertz-Sternberg P, Karasik A. Efficacy of liraglutide in a real-life cohort. Diabetes Ther. 2014;5:193-206.

20. Mulligan CM, Harper R, Harding J, Mcllwaine W, Petruckevitch A, McLaughlin DM. A retrospective audit of type 2 diabetes patients prescribed liraglutide in real-life clinical practice. Diabetes Ther. 2013;4:147-51.

21. World Medical Association Declaration of Helsinki. Ethical principles for medical research involving human subjects. Last amended by the 64th WMA General Assembly, Fortaleza, Brazil. 2013.

22. Vilsbøll T, Vora J, Jarlov H, Kvist K, Blonde L. Type 2 diabetes patients reach target glycemic control faster using IDegLira than either insulin degludec or liraglutide given alone. Clin Drug Investig. 2016;36:293-303.

23. Rodbard HW, Buse JB, Woo V, et al. Benefits of combination of insulin degludec and liraglutide are independent of baseline glycated haemoglobin level and duration of type 2 diabetes. Diabetes Obes Metab. 2016;18:40-8.

24. Novo Nordisk A/S. Xultophy summary of product characteristics. https://www.medicines.org.uk/emc/ medicine/29493. Accessed 26 Sept 2016. 